\title{
Communication
}

\section{New, Aqueous Radical (Co)Polymerization of Olefins at Low Temperature and Pressure}

\author{
Devid Hero ${ }^{1}$ and Gergely Kali ${ }^{1,2, *}$ \\ 1 Organic Macromolecular Chemistry, Saarland University, Campus C4.2, D-66123 Saarbrücken, Germany; \\ d.hero@mx.uni-saarland.de \\ 2 Center for Chemistry and Biomedicine, Department of Pharmaceutical Technology, Institute of Pharmacy, \\ University of Innsbruck, Innrain 80/82, 6020 Innsbruck, Austria \\ * Correspondence: gergelykali@gmail.com
}

Received: 8 May 2020; Accepted: 11 June 2020; Published: 12 June 2020

check for updates

\begin{abstract}
In this communication, we describe our preliminary results for the development of a new method of ethylene and propene (co)polymerization at low pressure at room temperature, using cyclodextrin-assisted aqueous radical polymerization for the first time. For polypropylene homopolymerization, the cyclodextrin was entirely removed, and the partially soluble polymer was characterized. The purification of polyethylene was not complete, since the threaded cyclodextrins remained on the polymer chain, enhancing its solubility and enable to analyze the sample. With this environmentally benign method, polyolefines could be produced, for the first time. The estimated yield was low, and therefore the conditions should be further tuned for industrial application. This straightforward approach could also be applied to synthesize poly(ethylene-co-vinyl acetate) copolymer with an ethylene content of $20 \mathrm{~mol} \%$ and enhanced yield. Although the procedure in this stage of research has some limitations, the theory behind can later be applied to develop new, energy-efficient, and versatile industrial processes for olefin copolymerizations for a wide range of comonomers.
\end{abstract}

Keywords: polyethylene; polypropylene; cyclodextrin; poly(ethylene-co-vinyl acetate); free-radical polymerization

\section{Introduction}

Polyolefines such as polyethylene and polypropylene, with the highest production and consumption volume in the world, are unquestionably the most important polymers in the world. For the industrial synthesis of low-density polyethylene (LDPE), free radical polymerization (FRP) of ethylene at high temperatures and pressures $\left(>>100{ }^{\circ} \mathrm{C}\right.$ and $>>1000$ bar $)$ is used $[1,2]$. This polymerization results in a branched structure wherein the degree of branching is determined by the pressure and temperature of the reaction. For the synthesis of an approximately linear polyethylene through FRP, a pressure of 5000 bar is required [1,2]. Polymerizations can also be performed both in bulk and in aqueous emulsion [3-11]. Not only linear polymers but also nanocomposites have been prepared by the polymerization of ethylene in emulsion [12-15]. There have been many attempts to carry out radical ethylene polymerization under milder conditions $\left(<100{ }^{\circ} \mathrm{C}\right.$ and $<1000$ bar) [16]. Still, these attempts were not of industrial interest because of the low yields achieved [17-21]. The radical polymerization is only possible for ethylene, but no other olefins, such as propylene, due to the rapid chain transfer caused by allylic hydrogen abstraction; therefore, industrial polypropylene synthesis uses Ziegler-Natta, or metallocene catalyst systems [1,2].

The radical copolymerization of ethylene with more reactive monomers such as styrene and vinyl acetate proceeds under significantly milder conditions than the homopolymerization of ethylene 
and therefore controlled polymerization techniques can also be used [22,23]. The copolymerization parameters of ethylene with the comonomers vinyl acetate and styrene usually differ from ideal copolymerization $\left(\mathrm{r}_{\text {ethylene }}=0.04-0.82\right.$, and $\left.\mathrm{r}_{\text {comonomer }}=0.99-2.00\right)$, but are tunable with pressure and temperature $[24,25]$. The copolymerization of ethylene and vinyl acetate at low-pressure and low-temperature yields only low molecular weights ( 10 kDa) [26-28], although higher molecular weights were achieved with cobalt-mediated radical polymerization (up to $35 \mathrm{kDa}$ ), the reaction was extremely slow [29]. Therefore, there is still a need for improved copolymerization processes of ethylene at low temperature and pressure.

The aforementioned aqueous emulsion polymerization of olefines applies a temperature above $80{ }^{\circ} \mathrm{C}$, pressure around and above 200 bars, and high amounts of hardly removable surfactants [12-16]. Cyclodextrins (CDs) are widely used to complex and solubilize different hydrophobic substances, even monomers, and polymers [30-32]. The hydrophobic cavity of CDs binds suitable organics by hydrophobic interactions and/or H-bonds, while the hydrophilic outer shell provides the water solubility. Ritter et al. successfully polymerized various hydrophobic monomers, such as styrene [33-38], (meth)acrylates [33,34,39-44], phenol derivatives [45,46], fumarates [47,48], dienes [49,50], halo-olefins [51-53], and other non-commercial ones [54-61] in water, solubilized by $\mathrm{CD}$, via free radical polymerization methods. During the polymerization, the $\mathrm{CD}$, every time, slips off from the last monomeric unit of the polymer, and the product precipitates, resulting in a pure product, or simple purification.

Here, we aim to test the $\mathrm{CD}$-assisted free radical polymerization in the production of polyolefins and their copolymers on a low-temperature and reduced pressure.

\section{Materials and Methods}

\subsection{Materials}

$\alpha$ - and $\beta$-cyclodextrins ( $\alpha$-, and $\beta-C D)$ were donated by Wacker Chemie (Münich, Germany) and was dried overnight under reduced pressure at $60{ }^{\circ} \mathrm{C}$. Ethylene $(99.9 \%$, Gerling Holz+Co, Germany), propylene (99.5\%, Air Liquide Deutschland GmbH, Germany), 2,2'-azobis [2"-(2'"'-imidazoline-2'"'-yl)propane] dihydrochloride (VA-044, 95\%, Fluorochem, Germany), and urea $(99.9 \%$, Grüssing GmbH, Germany) were used as received. Vinyl acetate ( $\geq 99 \%$, Sigma Aldrich, Germany) was freshly distilled under reduced pressure before used. Deuterated solvents (TCI Deutschland GmbH., Germany) were used as received.

\subsection{Methods}

\subsubsection{Polyethylene Prepared via Free Radical Polymerization}

A total of $242.5 \mathrm{mg}$ (0.75 mmol) 2,2'-azobis[2-(2-imidazoline-2-yl)propane] dihydrochloride (VA-044, radical initiator), was dissolved in $200 \mathrm{~mL} 30 \mathrm{wt} . \%$ aqueous $\alpha$-cyclodextrin $(\alpha-\mathrm{CD}, 60 \mathrm{~g}$, $61.70 \mathrm{mmol}$ ) suspension. The system was bubbled through with nitrogen gas for $30 \mathrm{~min}$ under stirring. Ethylene was added by 4.5 bar pressure, and the system was stirred for another $2 \mathrm{~h}$ in order to achieve $\alpha-\mathrm{CD} /$ ethylene complex formation. The reactor was heated to $35^{\circ} \mathrm{C}$ to start the reaction and was stirred for two days.

After the reaction, the resulting solid was filtered, dissolved in Dimethyl sulfoxide (DMSO), heated up to $60^{\circ} \mathrm{C}$, and was precipitated into aqueous $\mathrm{NaCl}$ solution $(5 \mathrm{wt} . \%)$. Yield $=0.6 \mathrm{~g}$

${ }^{1} \mathrm{H}$ NMR (DMSO-d6, $400 \mathrm{MHz}$ ) $\delta / \mathrm{ppm}=1.30 \mathrm{ppm}$ (methylene) for polyethylene. The broad, undefinable peaks around 3.0-4.0 ppm, $4.5 \mathrm{ppm}$, and 5.0-6.0 ppm belonging to threaded $\alpha$-CD ensure the solubility of polyethylene in DMSO. From the integral values, the ethylene/PEG molar ratio is 1/0.05. 


\subsubsection{Polypropylene Prepared via Free Radical Polymerization}

A total of $242.5 \mathrm{mg}(0.75 \mathrm{mmol})$ VA-044 was dissolved in $200 \mathrm{~mL}$ aqueous $8 \mathrm{M}$ urea/ $\beta$-cyclodextrin $(\beta-C D, 40 \mathrm{~g}, 41.12 \mathrm{mmol}$ ) solution. The system was bubbled through with nitrogen gas for $30 \mathrm{~min}$ under stirring. Propylene was added by 4.5 bar pressure, and the system was stirred for another $2 \mathrm{~h}$ in order to $\beta-\mathrm{CD} /$ propylene complex formation. The reactor was heated to $35^{\circ} \mathrm{C}$ to start the reaction and was stirred for two days.

After the reaction, the clear solution was purified by ultrafiltration (10 kDa MWCO). After freeze-drying, the resulting product was reprecipitated from DMSO into $0.1 \mathrm{M}$ aqueous $\mathrm{NaCl}$ solution. Yield $=1.0 \mathrm{~g}$

${ }^{1} \mathrm{H} \mathrm{NMR}\left(\mathrm{CDCI}_{3}, 400 \mathrm{MHz}\right) \delta / \mathrm{ppm}=0.80,1.25$, and $1.55 \mathrm{ppm}$ for the methyl methylene methine protons of polypropylene.

\subsubsection{Poly(Ethylene-co-Vinyl Acetate) Prepared via Free Radical Polymerization}

$242.5 \mathrm{mg}$ ( $0.75 \mathrm{mmol})$ VA-044 was dissolved in $200 \mathrm{~mL} 30 \mathrm{wt} . \%$ aqueous $\alpha$-CD (60 g, $61.70 \mathrm{mmol})$ suspension. $18.4 \mathrm{~mL}(17.2 \mathrm{~g}, 200 \mathrm{mmol})$ of vinyl acetate was added to this solution. The system was bubbled through with nitrogen gas for $30 \mathrm{~min}$ under stirring. Ethylene was added by 4.5 bar pressure, and the system was stirred for another $2 \mathrm{~h}$ in order to $\alpha-\mathrm{CD} /$ ethylene complex formation. The reactor was heated to $35^{\circ} \mathrm{C}$ in order to start the reaction and was stirred for two days.

After the reaction, the resulting whiteish gluey-solid was centrifuged. Yield $=12 \mathrm{~g}$

${ }^{1} \mathrm{H}$ NMR (DMSO-d6, $400 \mathrm{MHz}$ ) $\delta / \mathrm{ppm}=0.90-1.40 \mathrm{ppm}$ for methylenes with various connections of polyethylene, 1.75-2.00 ppm for methyl and methylene protons for poly(vinyl acetate), $4.87 \mathrm{ppm}$ (methine) of poly(vinyl acetate).

\subsubsection{Blind Tests and Reproducibility}

The same reactions as above were carried out without the addition of an initiator and cyclodextrin solubilizer. The same conditions and feed compositions were used as in Section 2.2.1 and Section 2.2.2, and the reaction mixture was kept at $35^{\circ} \mathrm{C}$ for three days. After the appropriate workup procedure, no products were found in these reactions.

The reproducibility of all the reactions was examined by successively performing three polymerizations with the above-mentioned monomers and reaction conditions.

\subsection{Analytical Methods}

The ${ }^{1} \mathrm{H}$ NMR measurements were performed on a Bruker AVANCE Ultrashield $400(400.2 \mathrm{MHz})$ instrument (Billerica, MA, USA).

IR spectra were obtained with a Bruker Tensor 27 Fourier transform infrared (FT-IR) spectrometer (Bruker Rheinfelden, Germany) in transmission mode using the software OPUS by Bruker.

Gel permeation chromatography of the polymer samples was performed with a standard setup that consisted of SDV 103 and 105 Å columns from Polymer Standards Service (PSS) (Mainz, Germany) and a Shodex RI-101 (Tokyo, Japan) refractive index detector. The mobile phase was chloroform and $\mathrm{THF}$, and the flow rate was $1.0 \mathrm{~mL} / \mathrm{min}$ at $25^{\circ} \mathrm{C}$ using a Viscotek VE1121 GPC pump. The column was calibrated with narrow linear polystyrene standards (PSS, from 1.04 to $1090 \mathrm{kDa}$ ). Data evaluation was performed with the WinGPC Unity 7 program (PSS).

\section{Results and Discussion}

First, the homopolymerization of ethylene and propene in water was tested via cyclodextrin (CD)-assisted radical polymerization.

Ethylene was complexed with $\alpha$-cyclodextrin in water, and the complex was polymerized using VA-044 radical initiator at $35^{\circ} \mathrm{C}$, as shown in Figure 1 . The monomer was added with 4.5 bar over the reaction; therefore, no long polymer chains or high yield was expected using such small pressure at 
around room temperature. After the $36 \mathrm{~h}$ of reaction, the white solid was centrifuged, dissolved in DMSO, and precipitated into $5 \mathrm{wt} . \% \mathrm{NaCl}$ solution. The product yielded as white solid around $0.6 \mathrm{~g}$, was lyophilized and analyzed.

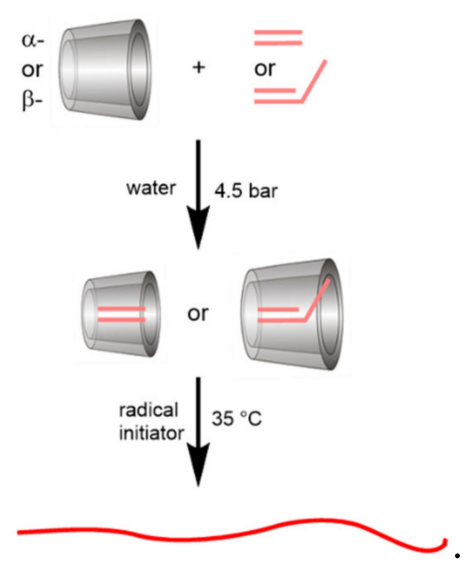

Figure 1. General scheme of the cyclodextrin-assisted aqueous radical polymerization of ethylene and propylene.

Because of the insolubility of polyethylene in most of the commercial solvents, the characterization of the polymer is challenging. The IR spectrum of the polymeric product (Figure S1) shows several different peaks. First, significant absorbances of CDs were seen in the fingerprint region and above $3000 \mathrm{~cm}^{-1}$. Strong peaks at 2800 and around $1500 \mathrm{~cm}^{-1}$ belonged to the $\mathrm{C}-\mathrm{H}$ stretching and bending, respectively. Even though the intensity of these second peaks was higher than that for pure CDs, the overlapping absorbances of the two components, i.e., polymer and CD, at these wavenumbers did not support the characterization of the product. Nevertheless, it can give some hint, and let us assume that, with CD-assisted polymerization, the resulting product still contained some threaded macrocycles. The threaded CDs provide the solubility of the polyethylene, facilitated to investigate via NMR spectroscopy (Figure S2).

The peaks around 3.0-4.0 ppm, and between 4.5 and 5.5 ppm belong to threaded $\alpha-C D$, which ensures the solubility of polyethylene in DMSO, while the chemical shift at 1.20 ppm belongs to the polyethylene. From the integral values of the methylenes of polymer and the anomeric proton of the cyclodextrin, the ethylene/CD molar ratio is $1 / 0.85$. These findings show that pseudo-polyrotaxanes of polyethylene and $\alpha$-CD have been formed, which was also supported by the fact that the CD peaks are broadened, because of their restricted mobility, as a consequence of threading.

Because of the strong hydrogen bonds between the native CDs, it can be assumed that the polymerization of the complexed monomer runs in a channel formed by the organization of the CDs [62]. Therefore, a small amount (five orders of magnitude lower than CD in moles) of poly(ethylene glycol) (PEG, Mn 35kDa) was added to the system. PEG forms pseudo-polyrotaxane with $\alpha$-CD in water [63], and due to the length of this additive, the development of more elongated channels, consequently longer polymers, is expected. Based on the NMR spectrum (see supporting information, Figure S3), it can be concluded that the PEG could not be removed from the system, but the ethylene/CD molar ratio significantly decreased to $1 / 0.35$.

Gel permeation chromatographic (GPC) investigation was not possible of this complex superstructure, because of the dynamics of threading-dethreading of CD from the polymer, in the mobile phase, resulted in precipitation in the column. For the same reason, molar mass determination with other simple methods, such as viscometry or osmometry, was not possible.

The radical polymerization of propylene is highly unfavorable because of the allylic hydrogen abstraction [1,2]. Based on the results of the CD-assisted aqueous radical polymerization of ethylene, propylene was also tested in this reaction (see general scheme in Figure 1). Propylene was added with 
4.5 bar to aqueous cyclodextrin solution. In this case, $\beta$ - instead of $\alpha-C D$ was used because propylene could not fit into the cavity of the $\alpha$ variant, with a low cross-section. $\beta-C D$ has only limited solubility in water but has enhanced solubility in a urea/water system; therefore, $8 \mathrm{M}$ aqueous urea was used as the reaction medium [22]. After $36 \mathrm{~h}$ of reaction, within similar conditions as the aforementioned ethylene, the clear solution was purified by ultrafiltration (10 kDa MWCO), and the resulting product was reprecipitated from DMSO into $0.1 \mathrm{M}$ aqueous $\mathrm{NaCl}$ solution. The $1.0 \mathrm{~g}$ white solid polymer product was analyzed via FT-IR and NMR spectroscopy.

From the IR spectrum of the produced polypropylene (Figure S4), the strong peaks of C-H stretching and bending at 2800 and around and below $1500 \mathrm{~cm}^{-1}$ can be identified, respectively. These are much stronger absorbances than those for $\mathrm{O}-\mathrm{H}$ stretching (above $3000 \mathrm{~cm}^{-1}$ ) for the CD solubilizer, meaning that only a tiny amount of threaded macrocycles are present.

Even polypropylene has low solubility in most of the common solvents; short oligopropylenes can be dissolved in chloroform. Hence, a fraction of the sample with a small degree of polymerization was dissolved for NMR and GPC analyses. Only three signals can be seen in the NMR spectrum (Figure 2) at $0.74,1.19,1.48 \mathrm{ppm}$, belong to the methyl, methylene and methine groups of oligo/polymeric propylene, formed in this aqueous polymerization, respectively. No, or very weak, peaks in CD are present, indicating almost complete purification after the reaction.

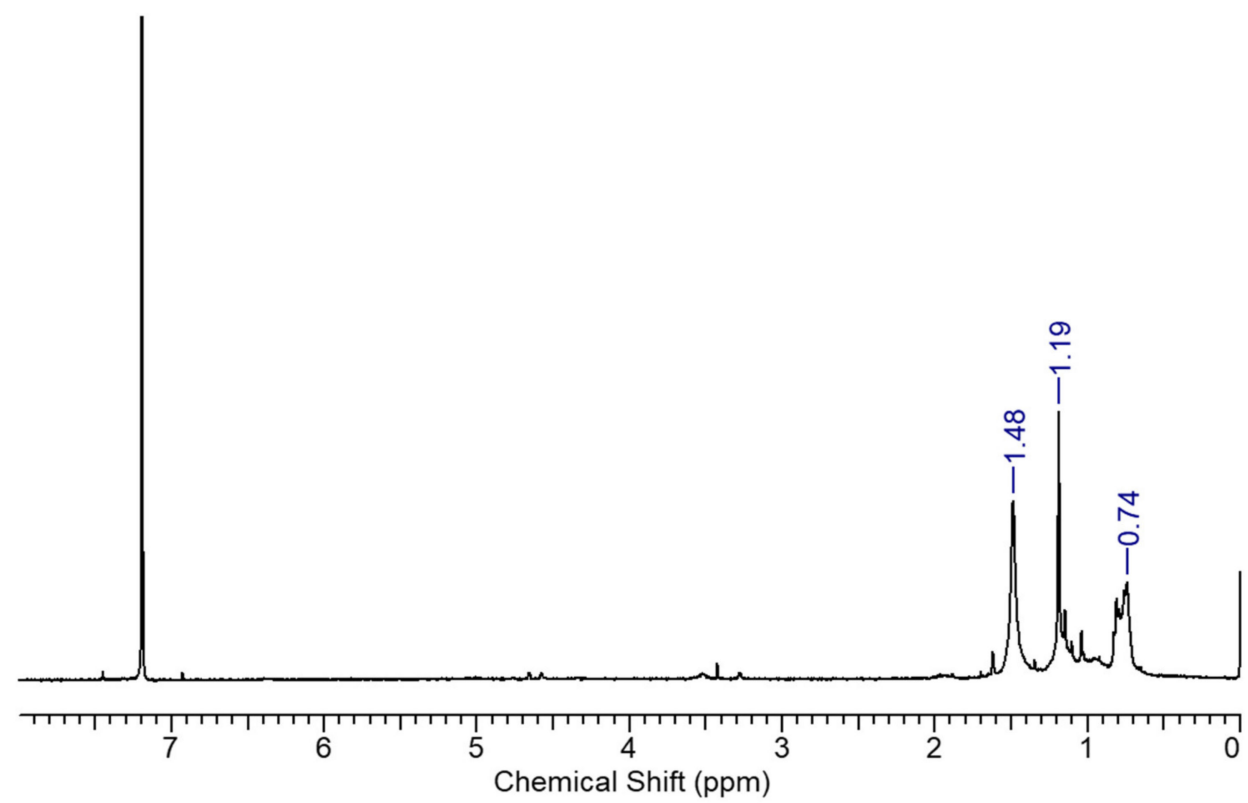

Figure 2. $400 \mathrm{MHz}{ }^{1} \mathrm{H}$ NMR spectrum of the polypropylene, produced via cyclodextrin (CD)-assisted aqueous free radical polymerization, in $\mathrm{CDCl} 3$.

The results of GPC chromatography (Figure S5) show multimodal molar mass distribution with molar masses up to $70 \mathrm{kDa}$. Some reservations have to be expressed about these results, due to the insolubility of the polypropylene, especially in the higher molar mass region, in the mobile phase.

The free-radical polymerization of propylene was possible, most probably because of some shielding effect of the cyclodextrin. Not only the monomer but also the polymeric chain-ends were complexed in the CD and no hydrogen abstraction; consequently, no chain transfer could have occurred.

Because of the problematic purification of polyethylene together with the low yield, copolymerization of ethylene was also investigated. The copolymer of ethylene and vinyl acetate is an important product; its application ranged from material science to biomedicine. $\alpha-C D$ assisted aqueous radical copolymerization of ethylene and vinyl acetate was carried out at $35{ }^{\circ} \mathrm{C}$, utilizing the previously used VA-044 thermal radical initiator. After $36 \mathrm{~h}$ reaction, the produced polymer was centrifuged and dried under vacuum, resulting in $12 \mathrm{~g}$ whiteish solid-gluey product. 
The IR spectrum (Figure 3) of the product, in comparison with the CD-assisted aqueous homopolymerization of ethylene, shows a strong absorbance at $1700 \mathrm{~cm}^{-1}$ for $\mathrm{C}=\mathrm{O}$ stretching, as an indication of the presence of vinyl acetate. The intensity of the broad $\mathrm{O}-\mathrm{H}$ stretching peak of $\mathrm{CD}$ is also decreased, in comparison to the homopolymerization trial, suggesting better purification than after the first polymerization.

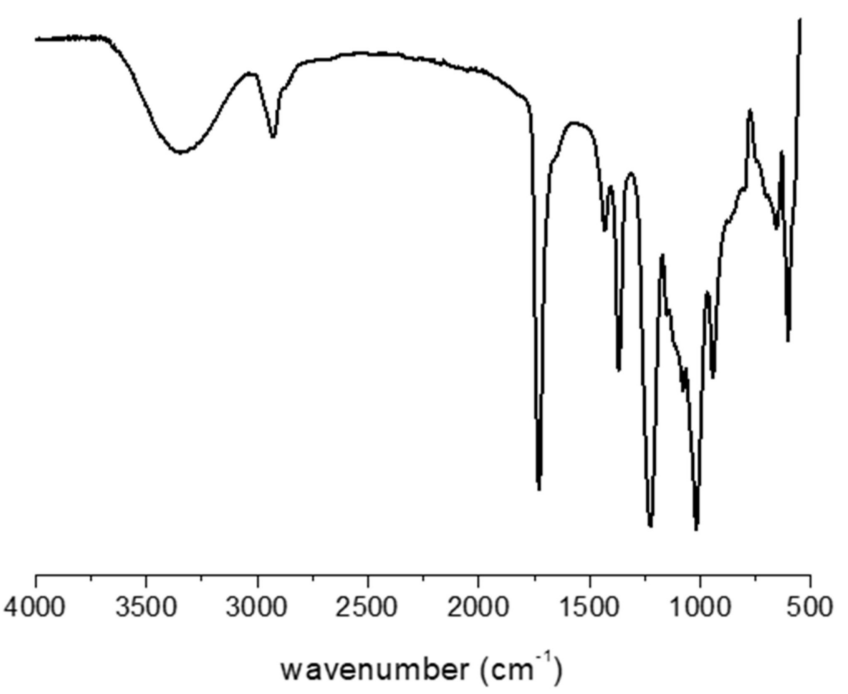

Figure 3. FT-IR spectrum of the poly(ethylene-co-vinyl acetate), produced via CD-assisted aqueous free radical polymerization.

The copolymer was partially soluble in apolar solvents, such as THF and chloroform. Even the formed clear solution, during sample preparation, particles were filtered out, with around $20 \mathrm{wt} . \%$ of the total product. Therefore, the results of the composition and molar mass determination, again, pertained to the soluble fraction.

From the NMR spectrum of the copolymer (Figure 4), the composition of the product could be calculated. The integral values of $\mathrm{CH}_{3}-\mathrm{O}$ - of the vinyl acetate at $4.85 \mathrm{ppm}$ and the polymeric backbone between 0.5 and $2.0 \mathrm{ppm}$ show that $20 \mathrm{~mol} \%$ ethylene and $80 \mathrm{~mol} \%$ of vinyl acetate built into the copolymer. This result suggests $57 \%$ monomer conversion for vinyl acetate. A lower pressure of ethylene was used in this reaction to test its effect on the composition. Two bars of ethylene led to very low olefin content, within the error range of integration of the NMR spectrum. Higher pressure could not be applied by our equipment.

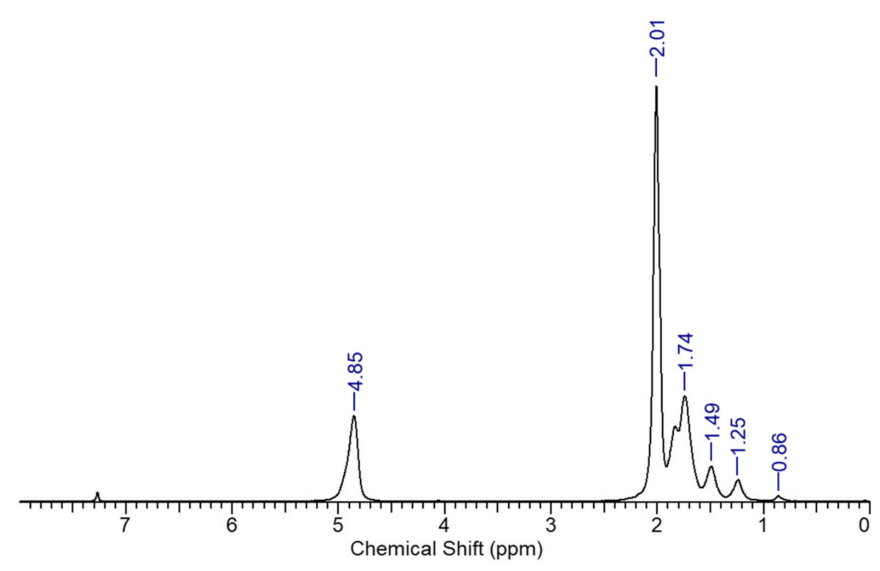

Figure 4. $400 \mathrm{MHz}{ }^{1} \mathrm{H}$ NMR spectrum of the poly(ethylene-co-vinyl acetate), produced via $\mathrm{CD}$-assisted aqueous free radical polymerization, in $\mathrm{CDCl}_{3}$. 
Molar mass was determined via GPC in tetrahydrofuran (THF). The molar mass of the soluble fraction of $85 \mathrm{kDa}$ was determined for the copolymer sample with a dispersity of 3.2 (Figure 5).

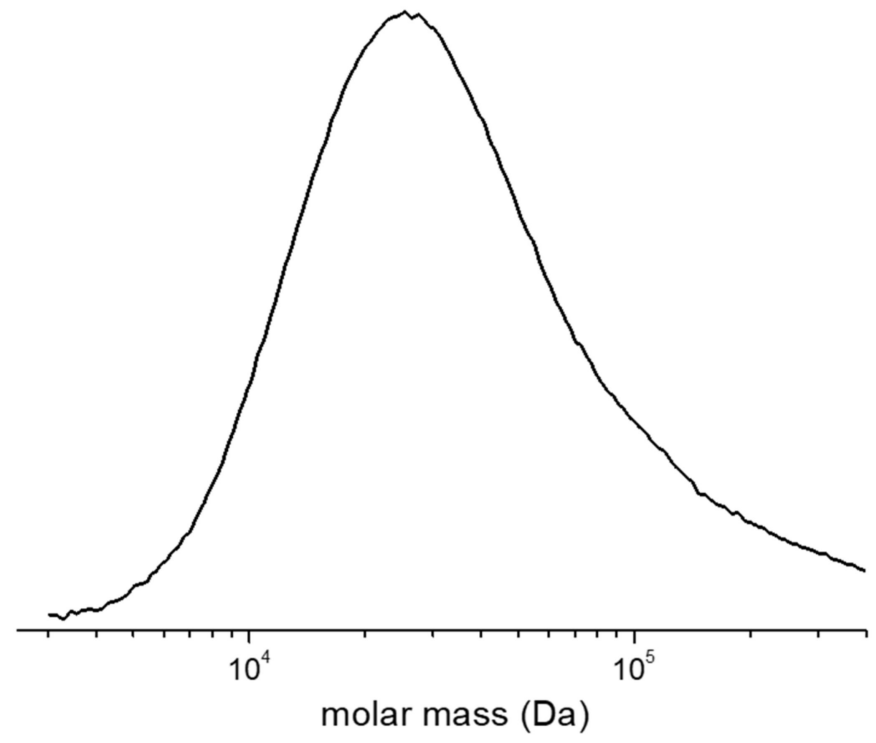

Figure 5. Molar mass distribution of poly(ethylene-co-vinyl acetate), produced via CD-assisted aqueous free radical polymerization, in THF.

Here, it should be noted that, for all the (co)polymerizations, test reactions were carried out without $C D$, initiator, or monomer. Neither homo- nor copolymerization resulted in a product when the initiator was not present. No product was detected in homopolymerizations either when CD or monomer was not added to the system. This result supports our assumption that only CD solubilized hydrophobic monomers have participated in these polymerizations.

\subsection{Recovery of the $C D$}

After all the reaction, the $\mathrm{CD}$ was recovered from the reaction mixture by ultrafiltration $(0.5 \mathrm{kDa}$ MWCO membrane), followed by freeze-drying. The regained macrocycles (up to $80 \%$ ) could be recycled and used in the further reaction, making the application of the solubilizer in such a high amount environmentally and financially not disadvantageous.

\subsection{Reproducibility of the Reactions}

In this early stage of the development of such a new method, the investigation of the reproducibility of the reaction is crucial. We repeated all the reactions several times, but at least three polymerizations with all monomers/comonomers were carried out. From the results of these reactions, we have learned that the reactions are satisfactorily reproducible, using the same workup procedure. For ethylene homopolymerization, the $\mathrm{CD}$ could be removed only until the above-mentioned limit, while propylene homopolymerization resulted in a pure product, always in the molar mass range $\sim 1-70 \mathrm{kDa}$. The copolymerization of ethylene and vinyl acetate resulted in a similar product every time, with a maximum deviation from the described results $\pm 5 \%$.

\section{Conclusions}

Ethylene and propylene were polymerized radically in water, close to room temperature, at low pressure, using cyclodextrin as a solubilizer, leading to polyolefines with a low yield. The purification of polyethylene was not ideal, but polypropylene could be easily separated from the CD. The copolymerization of ethylene and vinyl acetate resulted in a copolymer with $20 \mathrm{~mol} \%$ of ethylene content. This method opens new routes for environmentally friendly, energy-efficient, 
and inexpensive polyolefin synthesis and could lead to endless possibilities to generate a wide range of copolymers for these olefins. In the future, the effect of the pressure of the gaseous monomer on the product's molar mass and composition has to be investigated. It is highly expected that, at higher pressure, which consequently uses higher concentrations, the molar mass will be increased, and the purification will be more successful. Poly(ethylene-co-vinyl acetate) copolymer with a higher portion of ethylene can also be produced by utilizing higher ethylene pressure.

Supplementary Materials: The following are available online at http://www.mdpi.com/2227-9717/8/6/688/s1, Figure S1: IR spectrum of the formed polyethylene pseudorotaxane via cyclodextrin assisted aqueous radical polymerization of ethylene, Figure S2. $400 \mathrm{MHz} 1 \mathrm{H}$ NMR spectrum of the polyethylene, produced via CD assist-ed aqueous free radical polymerization, in d6-DMSO, Figure S3: $400 \mathrm{MHz} 1 \mathrm{H}$ NMR spectrum of the polyethylene, produced via CD assisted aqueous free radical polymerization with the addition of poly(ethylene glycol), in d6-DMSO, Figure S4: IR spectrum of the formed polypropylene via cyclodextrin assisted aqueous radical propylene polymerization, Figure S5. Molar mass distribution of the polypropylene, produced via CD assisted aqueous free radical polymerization, in chloroform.

Author Contributions: Conceptualization, G.K.; Methodology, D.H. and G.K.; Software, D.H. and G.K.; Validation, D.H. and G.K.; Formal analysis, D.H. and G.K.; Investigation, D.H. and G.K.; Resources, D.H. and G.K.; Data curation, D.H. and G.K.; Writing-Original draft preparation, D.H. and G.K.; Writing-Review and editing, G.K.; Visualization, D.H. and G.K.; Supervision, G.K.; Project administration, G.K. All authors have read and agreed to the published version of the manuscript

Funding: This research received no external funding.

Acknowledgments: First of all, Gerhard Wenz is gratefully acknowledged for all of his support for this work. The author is grateful for the GPC analyses of Blandine Bossmann. Wacker AG. is acknowledged for the donations of cyclodextrins.

Conflicts of Interest: The authors declare no conflict of interest.

\section{References}

1. Hines, R.A.; Bryant, W.M.D.; Larchar, A.W.; Pease, D.C. Synthesis of linear polyethylene by a free radical route at very high pressures. Ind. Eng. Chem. 1957, 49, 1071-1074. [CrossRef]

2. Malpass, D.B. Introduction to Industrial Polyethylene: Properties, Catalysts, Processes, Scrivener Pub; Wiley: Hoboken, NJ, USA, 2010.

3. Helin, A.F.; Stryker, H.K.; Mantell, G.J. Emulsion polymerization of ethylene. I. Polymerization formulas and conditions. J. Appl. Polym. Sci. 1965, 9, 1797-1805. [CrossRef]

4. Stryker, H.K.; Helin, A.F.; Mantell, G.J. Emulsion polymerization of ethylene. II. Effect of recipe on particle size and distribution. J. Appl. Polym. Sci. 1965, 9, 1807-1822. [CrossRef]

5. Stryker, H.K.; Helin, A.F.; Mantell, G.J. Emulsion polymerization of ethylene. III. Factors affecting the stability of polyethylene latexes. J. Appl. Polym. Sci. 1966, 10, 81-96. [CrossRef]

6. Mantell, G.J.; Stryker, H.K.; Helin, A.F.; Jamieson, D.R.; Wright, C.H. Emulsion polymerization of ethylene. IV. Effect of recipe and polymerization conditions on polymer properties. J. Appl. Polym. Sci. 1966, 10, 1845-1862. [CrossRef]

7. Stryker, H.K.; Mantell, G.J.; Helin, A.F. Emulsion polymerization of ethylene. V. Kinetics and mechanism. J. Appl. Polym. Sci. 1967, 11, 1-22. [CrossRef]

8. Stryker, H.K.; Mantell, G.J.; Helin, A.F. Kinetics and mechanism of the emulsion polymerization of ethylene. J. Polym. Sci. Part C Polym. Symp. 1969, 27, 35-48. [CrossRef]

9. Suwa, T.; Nakajima, H.; Takehisa, M.; Machi, S. Preparation of emulsifier-free polyethylene latecies by radiation polymerization. J. Polym. Sci. Polym. Lett. Ed. 1975, 13, 369-375. [CrossRef]

10. Brocks, R.E.; Peterson, M.D.; Weber, A.G. Process for Polymerizing Olefinic Materials. U.S. Patent US2388225A, 15 March 1941.

11. Dewey, P.M. Polymerization Process. U.S. Patent US2388178A, 30 October 1945.

12. Grau, E.; Dugas, P.-Y.; Broyer, J.-P.; Boisson, C.; Spitz, R.; Monteil, V. Aqueous dispersions of nonspherical polyethylene nanoparticles from free-radical polymerization under mild conditions. Angew. Chem. Int. Ed. 2010, 49, 6810-6812. [CrossRef] [PubMed]

13. Billuart, G.; Bourgeat-Lami, E.; Lansalot, M.; Monteil, V. Free radical emulsion polymerization of ethylene. Macromolecules 2014, 47, 6591-6600. [CrossRef] 
14. Brunel, F.; Billuart, G.; Dugas, P.-Y.; Lansalot, M.; Bourgeat-Lami, E.; Monteil, V. Crystallization of nanodomains in polyethylene latexes. Macromolecules 2017, 50, 9742-9749. [CrossRef]

15. Morgen, T.O.; Krumova, M.; Luttikhedde, H.; Mecking, S. Free-radical dispersion polymerization of ethylene with laponite to polyethylene-clay nanocomposite particles. Macromolecules 2018, 51, 4118-4128. [CrossRef]

16. Fawcett, E.W.; Gibson, R.O.; Perrin, M.W. Polymerization of Olefins. U.S. Patent US2153553A, 11 April 1939.

17. Lyubetskii, S.G.; Dolgoplosk, B.A.; Erusalimskii, B.L. Free radical polymerization of ethylene-III. Polymerization of ethylene under conditions of heterogeneity of the monomer-polymer system. Polym. Sci. USSR 1962, 3, 751-752. [CrossRef]

18. Wiley, R.H.; Lipscomb, N.T.; Johnston, F.J.; Guillet, J.E. Kinetics of the $\gamma$-radiation-induced polymerization of ethylene. J. Polym. Sci. 1962, 57, 867-879. [CrossRef]

19. Machi, S.; Hagiwara, M.; Gotoda, M.; Kagiya, T. Existence of long-lived radicals in the $\gamma$-radiation induced polymerization of ethylene. J. Polym. Sci. Part A Gen. Pap. 1965, 3, 2931-2934. [CrossRef]

20. Machi, S.; Sakai, T.; Tamura, T.; Gotoda, M.; Kagiya, T. The free radical polymerization of ethylene at low temperature. J. Polym. Sci. Part B Polym. Lett. 1965, 3, 709-713. [CrossRef]

21. Machi, S.; Hagiwara, M.; Gotoda, M.; Kagiya, T. Initiation and propagation in $\gamma$-radiation-induced polymerization of ethylene. J. Polym. Sci. Part A-1 Polym. Chem. 1966, 4, 1517-1529. [CrossRef]

22. Godoy Lopez, R.; D'Agosto, F.; Boisson, C. Synthesis of well-defined polymer architectures by successive catalytic olefin polymerization and living/controlled polymerization reactions. Prog. Polym. Sci. 2007, 32, 419-454. [CrossRef]

23. Chen, E.Y.-X. Coordination polymerization of polar vinyl monomers by single-site metal catalysts. Chem. Rev. 2009, 109, 5157-5214. [CrossRef] [PubMed]

24. German, A.L.; Heikens, D. Copolymerization of ethylene and vinyl acetate at low pressure: Determination of the kinetics by sequential sampling. J. Polym. Sci. Part A-1 Polym. Chem. 1971, 9, 2225-2232. [CrossRef]

25. Ehrlich, P.; Mortimer, G.A. Fundamentals of the free-radical polymerization of ethylene. Adv. Polym. Sci. 1970, 7, 386-448.

26. Buback, M.; Dröge, T. High-pressure free-radical copolymerization of ethene and butyl methacrylate . Macromol. Chem. Phys. 1999, 200, 256-264.

27. Buback, M.; Wittkowski, L.; Lehmann, S.A.; Mähling, F.-O. High-pressure free-radical copolymerization of ethene-methacrylic acid and of ethene-acrylic acid, 1. (Meth)acrylic acid reactivity ratios. Macromol. Chem. Phys. 1999, 200, 1935-1941. [CrossRef]

28. Buback, M.; Wittkowski, L. High-pressure free-radical copolymerization of ethene with methacrylic acid and ethene with acrylic acid, 2. Ethene reactivity ratios. Macromol. Chem. Phys. 2000, 201, 419-426. [CrossRef]

29. Bryaskova, R.; Willet, N.; Degée, P.; Dubois, P.; Jérôme, R.; Detrembleur, C. Copolymerization of vinyl acetate with 1-octene and ethylene by cobalt-mediated radical polymerization. J. Polym. Sci. Part A Polym. Chem. 2007, 45, 2532-2542. [CrossRef]

30. Borkar, A.; Sen, S. Controlled copolymerization of vinyl acetate with 1-alkenes and their fluoro derivatives by degenerative transfer. J. Polym. Sci. Part A Polym. Chem. 2005, 43, 3728-3736. [CrossRef]

31. Ritter, H.; Tabatabai, M. Cyclodextrin in polymer synthesis: A green way to polymers. Prog. Polym. Sci. 2002, 27, 1713-1720. [CrossRef]

32. Glöckner, P.; Metz, N.; Ritter, H. Cyclodextrins in polymer synthesis: Free-radical polymerization of methylated $\beta$-cyclodextrin complexes of methyl methacrylate and styrene controlled by $\mathrm{N}$-acetyl-L-cysteine as a chain-transfer agent in aqueous medium. Macromolecules 2000, 33, 4288-4290. [CrossRef]

33. Choi, S.W.; Amajjahe, S.; Ritter, H. Polymerization of included monomers and behaviour of resulting polymers. Adv. Polym. Sci. 2009, 222, 79-113.

34. Choi, S.W.; Ritter, H. Novel polymerization of myrcene in aqueous media via cyclodextrin-complexes. e-Polymers 2007, 7. [CrossRef]

35. Storsberg, J.; Ritter, H. Cyclodextrins in polymer synthesis: Free radical polymerization of cyclodextrin host-guest complexes of methyl methacrylate or styrene from homogenous aqueous solution. Macromol. Rapid Commun. 2000, 21, 236-241. [CrossRef]

36. Casper, P.; Glöckner, P.; Ritter, H. Cyclodextrins in polymer synthesis: Free radical copolymerization of methylated-cyclodextrin complexes of hydrophobic monomers with $\mathrm{N}$-isopropylacrylamide in aqueous medium. Macromolecules 2000, 33, 4361-4364. [CrossRef] 
37. Ritter, H.; Steffens, C.; Storsberg, J. Cyclodextrin in polymer chemistry: Kinetic studies on the free-radical polymerization of cyclodextrin-complexed styrene from homogeneous aqueous solution. e-Polymers 2013, 5. [CrossRef]

38. Alupei, I.C.; Alupei, V.; Ritter, H. Cyclodextrins in polymer synthesis: Crosslinking water-soluble unsaturated polyester resins using a cyclodextrin/styrene complex in aqueous medium. Macromol. Rapid Commun. 2003, 24, 527-531. [CrossRef]

39. Jeromin, J.; Ritter, H. Cyclodextrins in polymer synthesis: Free radical polymerization of a N-methacryloyl-11-aminoundecanoic acid/cyclodextrin pseudorotaxane in an aqueous medium. Macromolecules 1999, 32, 5236-5239. [CrossRef]

40. Glöckner, P.; Ritter, H. Cyclodextrins in polymer chemistry: Influence of methylated $\beta$-cyclodextrin as host on the free radical copolymerization reactivity ratios of isobornyl acrylate and butyl acrylate as guest monomers in aqueous medium. Macromol. Rapid Commun. 1999, 20, 602-605. [CrossRef]

41. Choi, S.; Ritter, H. Formation of physical polymeric gels during polymerization of cyclodextrin complexed tert-butyl methacrylate in aqueous medium. J. Macromol. Sci.-Pure Appl. Chem. 2005, 42, 321-325. [CrossRef]

42. Ritter, H.; Schwarz-Barac, S.; Stein, P. Cyclodextrins in polymer synthesis: Two-step reaction to aliphatic poly(methacrylimide) foams by thermal treatment of copolymers obtained from cyclodextrin complexes of tert-butyl methacrylate and various N-alkyl methacrylamides. Macromolecules 2003, 36, 318-322. [CrossRef]

43. Schwarz-Barac, S.; Ritter, H. Cyclodextrins in polymer synthesis: Free radical polymerization of a tert-butylmethacrylate-cyclodextrin host-guest system in aqueous medium. J. Macromol. Sci.-Pure Appl. Chem. 2003, 40, 437-448. [CrossRef]

44. Sarvothaman, M.K.; Ritter, H. Discriminating influence of $\alpha$ - and methylated $\beta$-cyclodextrins on complexation and polymerization of diacrylate and dimethacrylate monomers. Macromol. Rapid Commun. 2004, 25, 1948-1952. [CrossRef]

45. Reihmann, M.H.; Ritter, H. Oxidative oligomerization of cyclodextrin-complexed bifunctional phenols catalyzed by horseradish peroxidase in water. Macromol. Chem. Phys. 2000, 201, 798-804. [CrossRef]

46. Pang, Y.J.; Ritter, H.; Tabatabai, M. Cyclodextrins in polymer chemistry: Enzymatically catalyzed oxidative polymerization of para-functionalized phenol derivatives in aqueous medium by use of horseradish peroxidase. Macromolecules 2003, 36, 7090-7093. [CrossRef]

47. Choi, S.; Frank, W.; Ritter, H. Novel polymerization of diethyl fumarate and maleate in aqueous media via cyclodextrin-complexes. React. Funct. Polym. 2006, 66, 149-156. [CrossRef]

48. Choi, S.W.; Ritter, H. Towards green routes for polymer synthesis: Polymerization of cyclodextrin host-guest complexed diethyl fumarate and copolymerization with complexed styrene in homogenous aqueous solution. Macromol. Rapid Commun. 2004, 25, 716-719. [CrossRef]

49. Groenendaal, L.; Ritter, H.; Storsberg, J. Method for Producing Polymers on the Basis of 1,3. Dienes. Patent WO2001038408A2, 31 May 2001.

50. Van Aert, H.; Storsberg, J.; Ritter, H.; Van Roost, C. Method of Preparing Polymer Particles Having Narrow Particle Size Distribution. U.S. Patent US6800709B2, 18 May 2001.

51. Kretschmann, O.; Ritter, H. Copolymerization of fluorinated monomers with hydrophilic monomers in aqueous solution in presence of cyclodextrin. Macromol. Chem. Phys. 2006, 207, 987-992. [CrossRef]

52. Choi, S.W.; Kretschmann, O.; Ritter, H.; Ragnoli, M.; Galli, G. Novel polymerization of fluorinated 2-vinylcyclopropane in aqueous solution via cyclodextrin complexes. Macromol. Chem. Phys. 2003, 204, 1475-1479. [CrossRef]

53. Storsberg, J.; Ritter, H. Cyclodextrins in polymer synthesis: A "green" route to fluorinated polymers via cyclodextrin complexes in aqueous solution. Macromol. Chem. Phys. 2002, 203, 812-818. [CrossRef]

54. Fischer, M.; Ritter, H. Cyclodextrins in polymer synthesis: Free radical polymerization of cyclodextrin complexes with oxazoline-functionalized vinyl monomers as guest molecules in aqueous medium. Macromol. Rapid Commun. 2000, 21, 236-241. [CrossRef]

55. Storsberg, J.; Ritter, H.; Pielartzik, H.; Groenendaal, L. Cyclodextrins in polymer synthesis: Supramolecular cyclodextrin complexes of pyrrole and 3,4-ethylenedioxythiophene and their oxidative polymerization. Adv. Mater. 2000, 12, 567-569. [CrossRef]

56. Schönenberg, L.; Ritter, H. Infl uence of $\beta$-Cyclodextrin on the Free-Radical Copolymerization of N-(4-Methylphenyl) maleimide with N-vinylpyrrolidone in Water. Macromol. Chem. Phys. 2013, 214, 2540-2545. [CrossRef] 
57. Ritter, H.; Mondrzik, B.; Rehahn, M.; Gallei, M. Free radical homopolymerization of a vinylferrocene/cyclodextrin complex in water. Beilstein. J. Org. Chem. 2010, 6, 60. [CrossRef]

58. Mejias, L.; Schollmeyer, D.; Sepulveda-Boza, S.; Ritter, H. Cyclodextrins in polymer synthesis: Enzymatic polymerization of a 2,6-dimethyl- $\beta$-cyclodextrin/2,4-dihydroxyphenyl-4'-hydroxybenzylketone host-guest complex catalyzed by horseradish peroxidase (HRP). Macromol. Biosci. 2003, 3, 395-399. [CrossRef]

59. Schwarz-Barac, S.; Ritter, H.; Schollmeyer, D. Cyclodextrins in polymer synthesis: enantiodiscrimination in free-radical polymerization of cyclodextrin-complexed racemic. Macromol. Rapid Commun. 2003, 24, 325-330. [CrossRef]

60. Theis, A.; Ritter, H. Cyclodextrins in polymer synthesis: Free radical polymerization of $\beta$-cyclodextrin complexes of photosensitive mesoionic 6-Oxo-1,6-dihydropyrimidin-3-ium-4-olates in aqueous medium. Macromol. Chem. Phys. 2003, 204, 1297-1304. [CrossRef]

61. Heinenberg, M.; Ritter, H. Cyclodextrins in polymer synthesis: Steric retardation of the free-radical polymerization in aqueous medium of 4 -vinylbenzaldehyde/methylated $\beta$-cyclodextrin complex. Macromol. Chem. Phys. 2002, 203, 1804-1810. [CrossRef]

62. Uyar, M.; Rusa, A.E.; Tonelli, T. Polymerization of styrene in cyclodextrin channels: Can confined free-radical polymerization yield stereoregular polystyrene? Macromol. Rapid Commun. 2004, 25, 1382-1386. [CrossRef]

63. Wenz, G. Recognition of monomers and polymers by cyclodextrins. Adv. Polym. Sci. 2009, 222, 1-54.

(C) 2020 by the authors. Licensee MDPI, Basel, Switzerland. This article is an open access article distributed under the terms and conditions of the Creative Commons Attribution (CC BY) license (http://creativecommons.org/licenses/by/4.0/). 